\title{
NEW POSSIBILITY OF OBJECTIVE EVALUATION OF YARN APPEARANCE
}

\author{
Eva Mouèková, Petra Jirásková
}

Technical University of Liberec, Faculty of Textile Engineering, Department of Textile Technologies, Liberec, Czech Republic E-mail: eva.mouckova@tul.cz, petra.jiraskova@tul.cz

\begin{abstract}
:
The possibility of new and objective evaluation of yarn appearance wound on the board is described. A statistical method which has previously been used for the evaluation of surface unevenness of flat textile - semivariograms is used. The yarn board appearance is converted into a grey-scale image and the fluctuation in degrees of greyness between square fields in the image is evaluated by semivariogram. This method was applied on standard yarn boards from the standard CSN 800704 in addition to real yarn boards. The results of semivariograms constructed from a simulated ideal appearance of yarn on the board are discussed with the aim of introducing an ideal case behaviour of semivariograms. The possibility of using this function for the objective evaluation of yarn board appearance is also discussed.
\end{abstract}

\section{Key words:}

Surface unevenness, semivariogram, yarn appearance, greyness degree.

\section{Introduction}

Yarn appearance is one of the parameters for a yarn quality evaluation. In practice, the yarn appearance is evaluated subjectively by comparing a yarn board of defined winding density with a standard yarn board according to ASTM D 225590, Standard Test Method for Grading Spun Yarns for Appearance [1], or according to the standard CSN 800704 Determination of yarn appearance, which is used in the Czech Republic [2].

The standard CSN divides yarn appearance into six quality classes (grades A - F) in five categories of fineness, and a photo of a yarn board is available for each yarn grade. The boards labelled by a letter A represent the best quality and subsequent letters refer to yarns of progressively lower quality. According to the standard ASTM, the yarn appearance is divided into four quality classes (grade A - D) in six categories of fineness, and a printed photo of a yarn board is available for each grade. The evaluation is dependent on the reviewer and their ability to visually compare the appearance of the yarns. Greater objectivity can be achieved by evaluation from a larger number of independent evaluators.

In practice, evaluation of the yarn appearance is mostly subjective, but there have been methods developed for objective evaluation. The work by [3], described a quantitative method for grading spun yarn appearance derived from optical yarn diameter measurements. Semnani et al., [4] introduced a method for grading various types of yarn appearance by using image analysis and an artificial neural network. The work by [5], described a new device for evaluating a yarn on the surface as an independent formation.

One of the important factors influencing the appearance of the yarn is its irregularity and it has been suggested that using selected statistical functions [6-7] that have already been used for the evaluation of surface unevenness of flat textiles [8-10], could be used for the evaluation of the yarn appearance on the board. Essentially, a sample of the flat textile is divided into square fields, where individual properties are measured and a so-called area-variation curve can be constructed. This curve is also used in the works [11-12] as a quantitative evaluation of the quality of the predicated image of the plain textile and it has been suggested as a new evaluation method of woven fabric unevenness [13]. Other statistical functions that make it possible to describe the surface variability, use the fact that the magnitude $z(x, y)$ is a random function of two variables (a random field). For example, a co-variation function, or a socalled directional semivariograms belong to these functions $[7,14-15]$ and the semivariogram has been used for describing the surface variability of woven and nonwoven fabrics [8-10].

For the evaluation of surface unevenness, both generated images of the appearance of the textile in area (yarn board, woven fabrics, knitted fabrics), and images of real fabrics or yarn board can be used. The real image of a grey textile is converted into greyness degrees and different grey levels reflect the unevenness of the textile, or in the case of a yarn, its faults. Thus, surface unevenness of a textile can be converted into the unevenness of colour of fabric images. The yarn mass irregularity and yarn faults also show themselves as nonuniformity in a colour image. The fluctuation of average greyness degrees in the image can be evaluated by means of mentioned statistical functions.

In this work semivariograms were used for the evaluation of the appearance of yarn wound on the board. These methods are applied to standard yarn boards from the standard CSN 800704 as well as real yarn boards. The results are compared with the semivariograms constructed from simulated ideal yarn appearance on the board and the possibility of using this function for the objective evaluation of yarn board appearance is discussed.

\section{Description of selected statistical function}

The semivariogram is a statistical function whereby the variability of random field properties is evaluated. In this case, the yarn board was converted into greyness degrees and divided into the square fields like a net. The observed property (greyness degrees) can be expressed as: $z=z(x, y)=z(x)$ in the net. The semivariogram expresses spatial dissimilarity between values at point $x_{i}$ and $x$. Generally, it is defined as one-half variance of differences $z\left(x_{i}\right)-z\left(x_{i}+\right.$ lag) [7, 14-16]. The magnitude lag is a directional vector representing separation 
between two spatial locations. For uniformly distributed points, $x$ values of vector lag express the multiples of distance between squares in the direction of columns $\left(0^{\circ}\right)$, rows $\left(90^{\circ}\right)$ and diagonals $\left(45^{\circ}\right)$ [7]. Thus, three types of semivariograms are obtained and an omni-directional semivariogram is calculated by the averaging of these three types of semivariograms.

We used the so-called centred sample semivariogram [15], which is constructed when a random field is non-stationary (average value in each field is not constant):

$$
G(\operatorname{lag})=\frac{1}{2 N(\operatorname{lag})} \sum_{i=1}^{N(\operatorname{lag})}\left(z_{c}\left(x_{i}\right)-z_{c}\left(x_{i}+\operatorname{lag}\right)\right)^{2}
$$

where: $z_{c}\left(x_{i}\right)$ is the centred average greyness degree defined as:

$$
z_{c}\left(x_{i}\right)=\frac{\sum_{i=1}^{n\left(x_{i}\right)} z\left(x_{i}\right)}{n\left(x_{i}\right)}
$$

$N$ (lag) is the number of pairs of observations separated by distance lag; $z\left(x_{i}\right)$ is the greyness degree at the location $x_{i}$. The image is divided into square fields like a net. The centres of the fields are the locations $x$. The average value of greyness degree in the given square field is assigned to the location $x$ $\left(z\left(x_{i}\right)\right)$. If $G($ lag $)=$ const., the magnitude $z($.$) is not correlated in$ the given direction.

\section{Experiment}

For the experiment we used:

a) Real standard yarn boards (called etalons) - from CSN 80 0704 - see Table 1 and for an example, see Figure 1.

Table 1. Etalon characteristics.

\begin{tabular}{|c|c|c|}
\hline $\begin{array}{c}\text { Etalon } \\
\text { grade }\end{array}$ & $\begin{array}{c}\text { Fineness of yarn } \\
\text { wound on etalons [tex] }\end{array}$ & $\begin{array}{c}\text { Winding density } \\
\text { [threads.cm }\end{array}$ \\
\hline A - F & 60 & 8 \\
\hline A - F & 30 & 12 \\
\hline A - F & 16,5 & 16 \\
\hline A - C & 10 & 16 \\
\hline A - C & 6 & 22 \\
\hline
\end{tabular}

b) Real yarn boards of two qualities - yarn without faults and yarn with short term irregularity caused the moiré effect (see Figures $2 \mathrm{a}$ and $2 \mathrm{~b}$ )

All yarn boards were scanned. The scanning resolution was $300 \mathrm{dpi}$ and the images obtained were saved in a noncompressed tiff format.

During the experiment, graphical simulations of ideal yarns wound on the board of a size corresponding to the etalons were created (Figures $3 a-3 c)$. They were done for determining the ideal course of semivariograms. Light stripes in the simulated image represent the yarn. Their width was determined by calculating yarn diameter according to equation (3) presented in [17], and converting the results to an integer number of pixels. Dark colour represents the board. Spacing between the light stripes was fixed so that the number of stripes per $\mathrm{cm}$ corresponded with the winding of the standard yarn board. The colours match the colours of the standard. In the

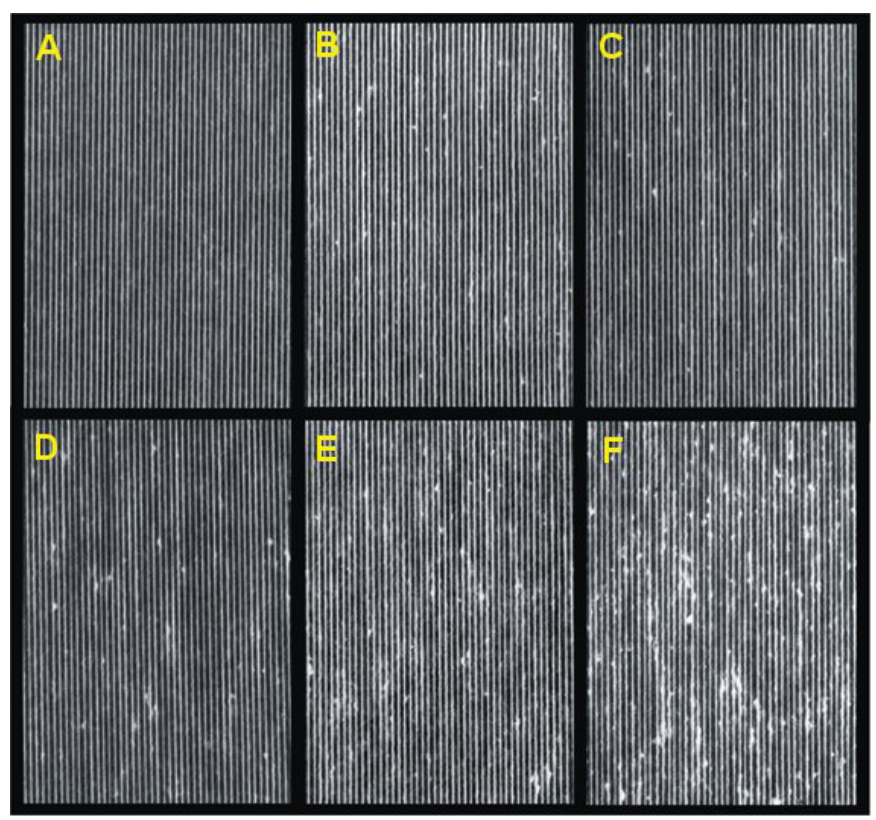

Figure 1. Standard yarn board (CSN) - grade A (the best) - grade $F$ (the worst), 100\% CO yarn - fineness 60 tex; original size $1547 \times 2677$ pxl, resolution 300 dpi.

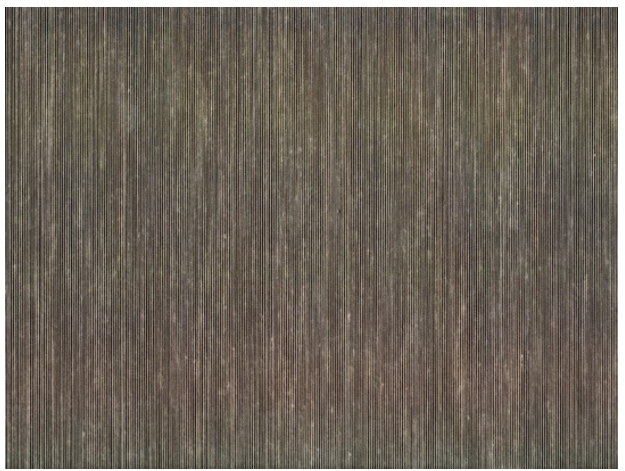

Figure 2a. Real yarn board - yarn without fault, $100 \%$ CO yarn fineness 30 tex; original size $3381 \times 2536$ pxl, resolution $300 \mathrm{dpi}$.

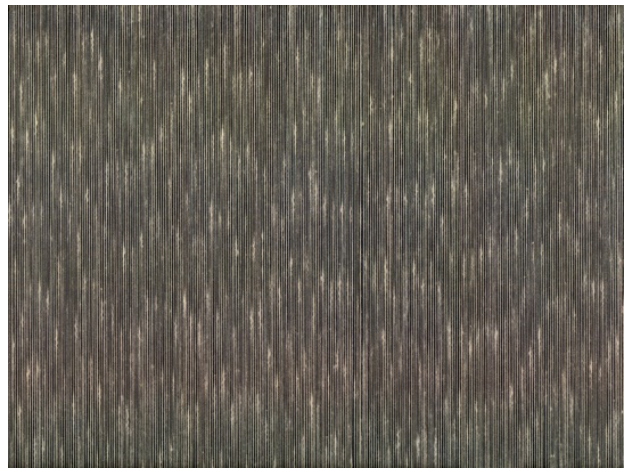

Figure $\mathbf{2 b}$. Real yarn board - yarn with moiré effect, $100 \%$ CO yarn fineness 30 tex; original size $3381 \times 2536$ pxl, resolution $300 \mathrm{dpi}$.

simulation, the yarn hairiness and unevenness was not taken into account.

$$
D=\sqrt{\frac{4 T}{\pi \mu \rho}}
$$

where: $\mathrm{T}$ is yarn fineness [tex], $\mu$ is yarn packing density [-] (here considered 0,5 ), and $\rho$ is density of cotton yarn [kg.m-3] (here considered $1520 \mathrm{~kg} \cdot \mathrm{m}-3$ ). 


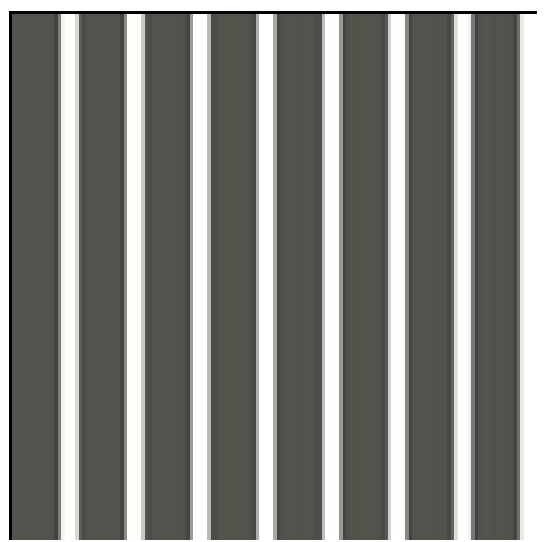

a)

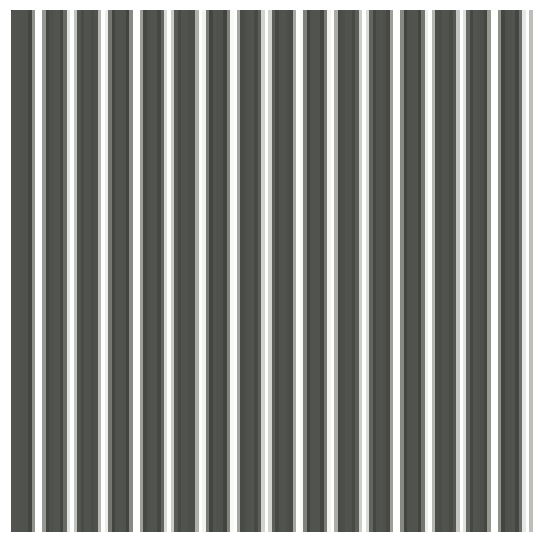

b)

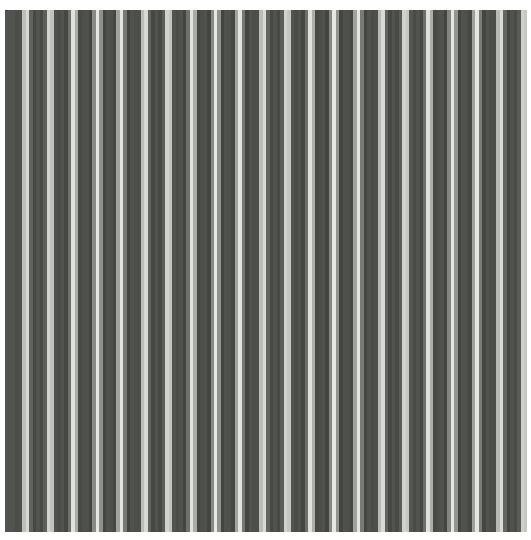

c)

Figure 3. Graphical simulation of ideal yarn - cut-out $1 \times 1 \mathrm{~cm}$, resolution 300 dpi - various yarn fineness as well as winding density; a) 60 tex; b) 16,5 tex; c) 6 tex.

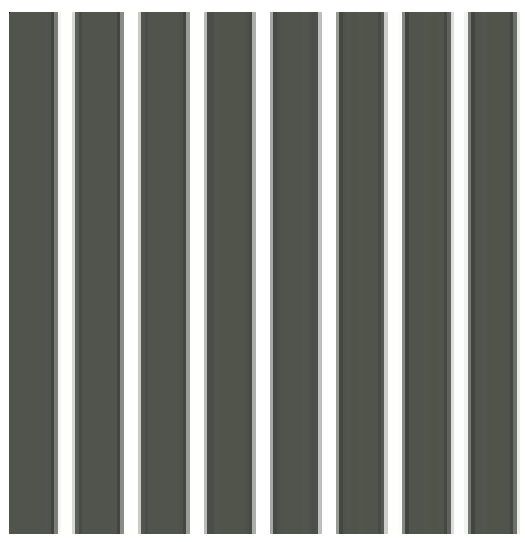

a)

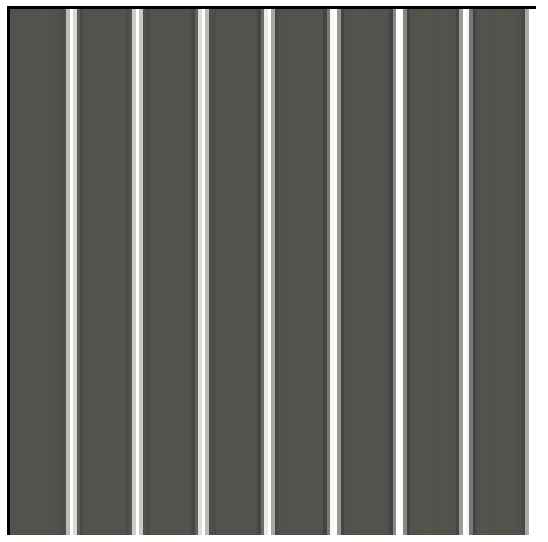

b)

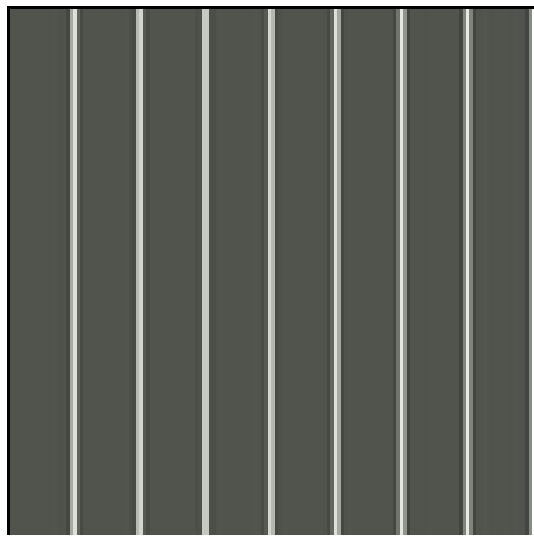

c)

Figure 4. Graphical simulation of ideal yarn board - cut-out $1 \times 1 \mathrm{~cm}$, resolution 300 dpi - the same winding density, various yarn fineness: a) 60 tex; b) 16,5 tex, c) 6 tex.

For comparison, the simulated yarn boards of yarn with varying fineness, but the same winding density were constructed see Figure 4.

All images were treated as described in "Fabric unevenness" written by Militký, J. (Technical University of Liberec), in the Matlab programming environment, which converts images to grey scale. In the case of semivariograms, the image converted into greyness degrees is divided it into square fields of a selected size; step $\times$ step pixels. The average greyness degree $\left(z\left(x_{i}\right)\right)$ is calculated for each field and from the values obtained the centred semivariogram in a given direction is calculated according to the formula (1). The size of the evaluated image area was $1500 \times 1500$ pixels from the centre of the image. The selected sizes of the parameter step were $3 \mathrm{pxl}$ and $15 \mathrm{pxl}$.

\section{Results and discussion}

\section{Graphical simulation of ideal yarn boards}

Directional semivariograms of greyness degrees were constructed from the simulated ideal yarn boards for a step size of $3 \mathrm{pxl}$ (Figure 5), and $15 \mathrm{pxl}$ (Figure 6).

It is evident from Figure 5, that the size of the parameter step influences the course of the semivariogram. With an appropriate choice of the parameter step, it is possible to identify stripes in the image, i.e., individual winds, by means of a combination of semivariograms in the direction of the columns and the rows. In the case with the parameter step of
$3 \mathrm{pxl}$, the period of the curve $\Delta / a g=5$, at resolution $300 \mathrm{dpi}$, corresponds to $15 \mathrm{pxl}$ in the image. It is the sum of the width of light stripes (yarn) and dark stripes (spacing between yarns), i.e., the period of curve multiplying the parameter step gives the size of the regularly repeating areas with the same level of greyness degrees. If the size of parameter step is the sum of the width of two neighbouring stripes of various colours, regularly repeating in the image, the course of the curve is constant, and equal to zero. This is because, as mentioned above, the parameter step defines the size of the square by which the image is divided before calculating. Then, the average centre greyness degree is calculated for each square and in the case of our simulated ideal yarn boards the squares contain the same values of average greyness degrees.

Winding density affects the course of the curve in terms of shape of periodical fluctuation, and in some cases, also in terms of the length of the period due to size of parameter step, the width of the stripe and length of period. Yarn fineness (width of stripes) influences the height of the maximum of the periodical fluctuations.

\section{Standard yarn boards (etalons)}

Directional semivariograms of greyness degrees constructed from standard yarn boards are mentioned in the Figure 7 (step $3 \mathrm{pxl}$ ), and Figure 8 (step $15 \mathrm{pxl})$.

The course of the semivariograms of greyness degrees of individual etalons is dependent on the size of parameter step. 


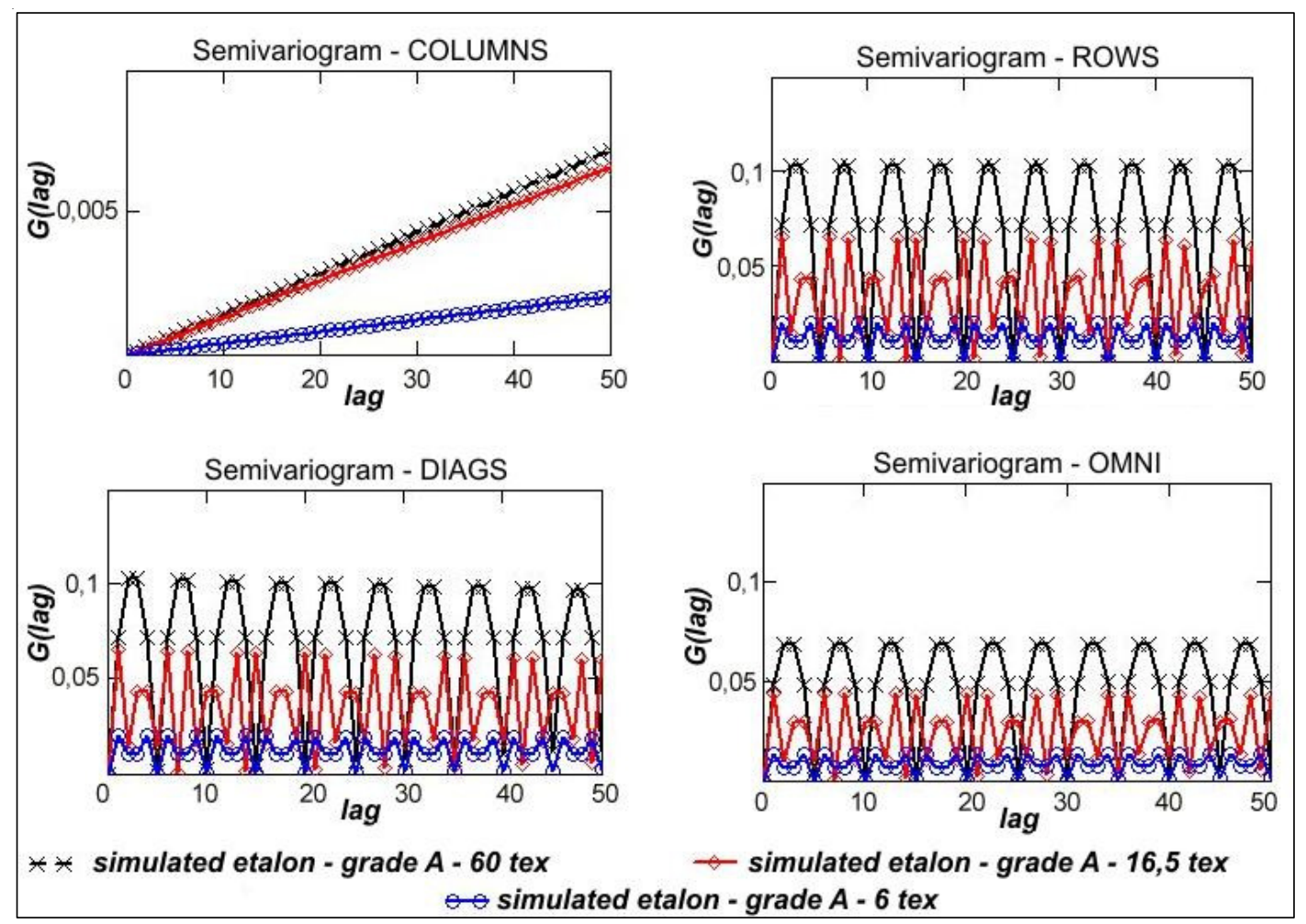

Figure 5. Directional semivariograms - simulated ideal yarn board - various yarn fineness, various winding density - step 3 - zoomed.
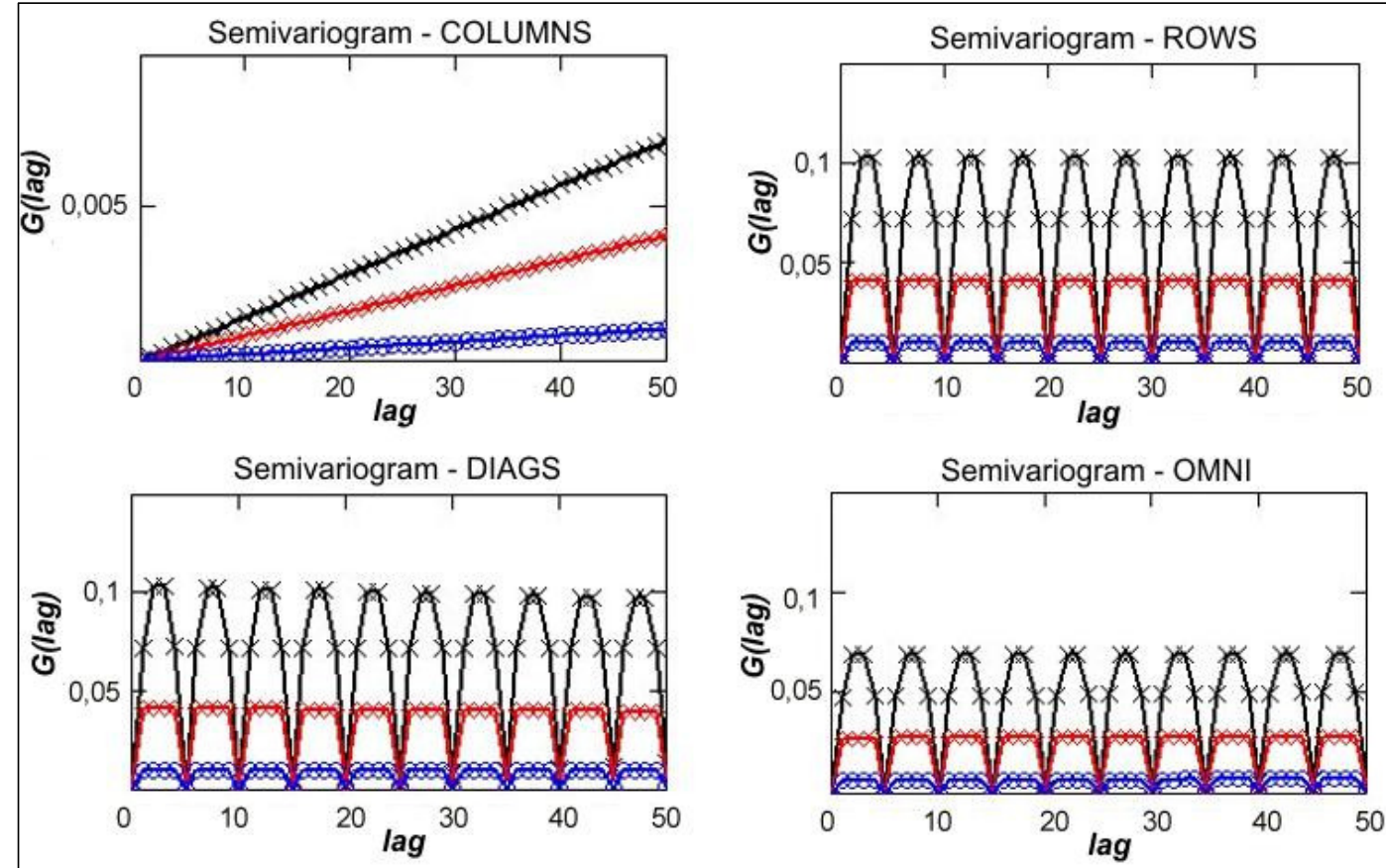

* $*$ simulated etalon - grade $A-60$ tex

$\smile$ simulated etalon - grade $A-16,5$ tex

simulated etalon - grade $A$ - 6 tex

Figure 6. Directional semivariograms - simulated ideal yarn board - various yarn fineness, the same winding density (8 threads $/ \mathrm{cm}$ ) - step 3 - zoomed.

A small size of parameter step is less suitable for evaluation of the yarn appearance on the board. The course of a semivariogram records the structure of the yarn winding on the board, i.e., the regularity of winding and for our purpose, the combination of semivariograms in the direction of rows and in the direction of columns seems to be the most suitable (Figure 7). The courses of the semivariogram in the direction of columns of etalon B were probably influenced by a lower quality of the scanned etalon. This etalon was a little corrugated due to its age and after scanning, the corrugation probably shows itself as a higher variability of greyness degrees between small areas in some places of the etalon. This could be a reason why the curve of etalon $B$ has different a course compared to the others.

From the semivariograms with step at $15 \mathrm{pxl}$ (Figure 8), a difference between the best (grade A) and the worst (grade F) 

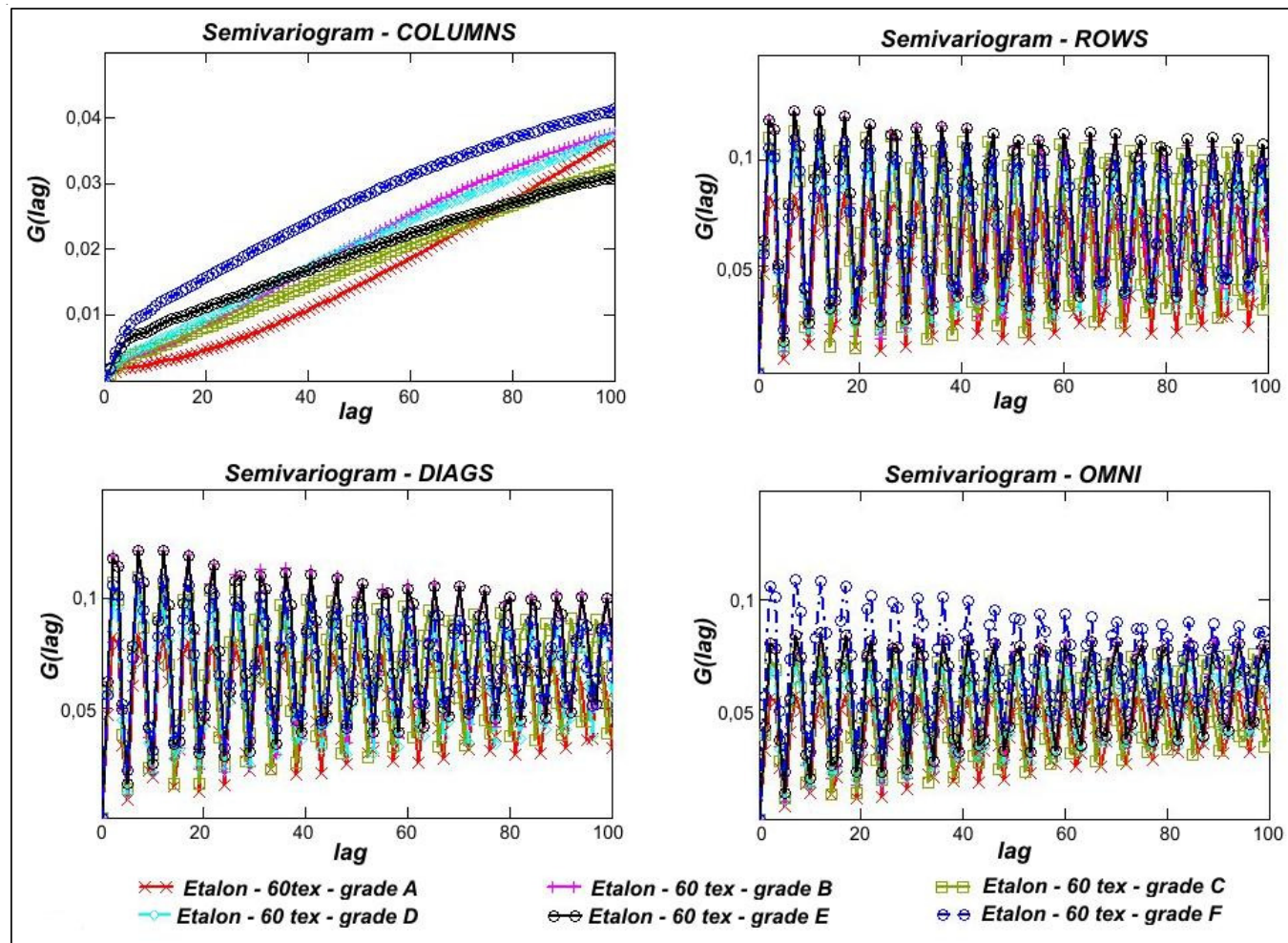

Figure 7. Directional semivariograms - etalons - yarn fineness 60 tex - step 3 pxl - zoomed.
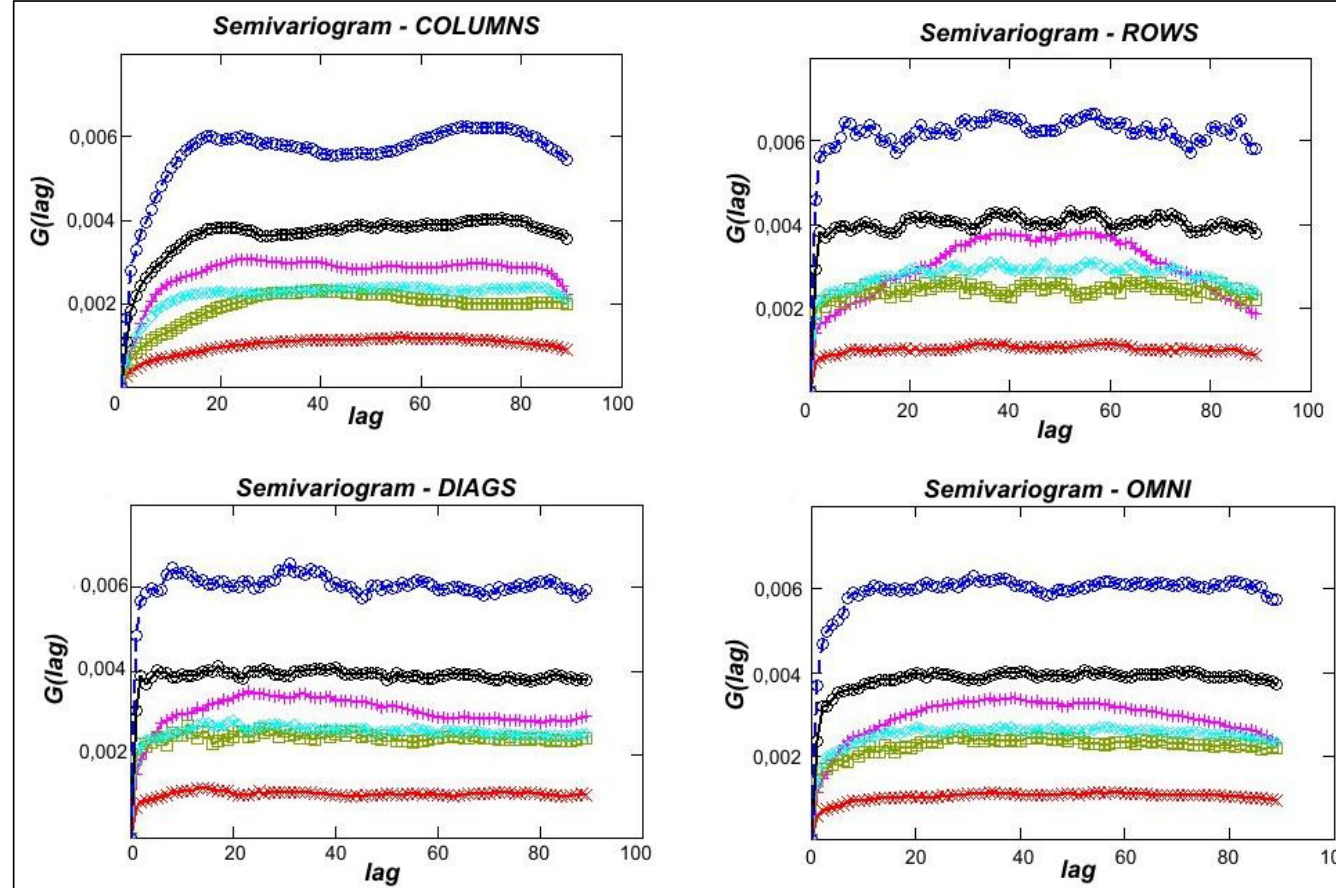

$*$ Etalon - 60tex - grade $A$
- Etalon - 60 tex - grade $D$

† Etalon - 60 tex - grade $B$

$\because \boxminus$ Etalon - 60 tex - grade $C$ Etalon - 60 tex - grade $E$

$\ominus \ominus$ Etalon - 60 tex - grade $F$

Figure 8. Directional semivariograms - etalons - yarn fineness 60 tex - step 15 pxl.

etalons is clearly evident. With a deteriorating grade of yarn appearance the curves of the semivariograms lie higher in the graph (except grade B), and exhibit a more fluctuating course. This is probably caused by the fact, that due to worsening yarn appearance (thin, thick places, hairiness) the image of the yarn board is unbalanced in colour and thus there is a bigger difference in the average values of greyness degrees between the evaluated square fields. Subjectively evaluating the etalons, it is difficult to find any marked differences between grades $\mathrm{C}$ and $D$. The positions of the curves on all the semivariograms are nearly identical. The etalon of grade $B$ was a little corrugated due to its age, and after scanning, the corrugation probably shows itself as a higher variability of greyness degrees between small areas in some parts of the etalon, and this could be the reason why the curve of etalon $B$ lies above the curves of etalons $\mathrm{C}$ and $\mathrm{D}$.

In Figure 9, the courses of the semivariograms from all etalons 


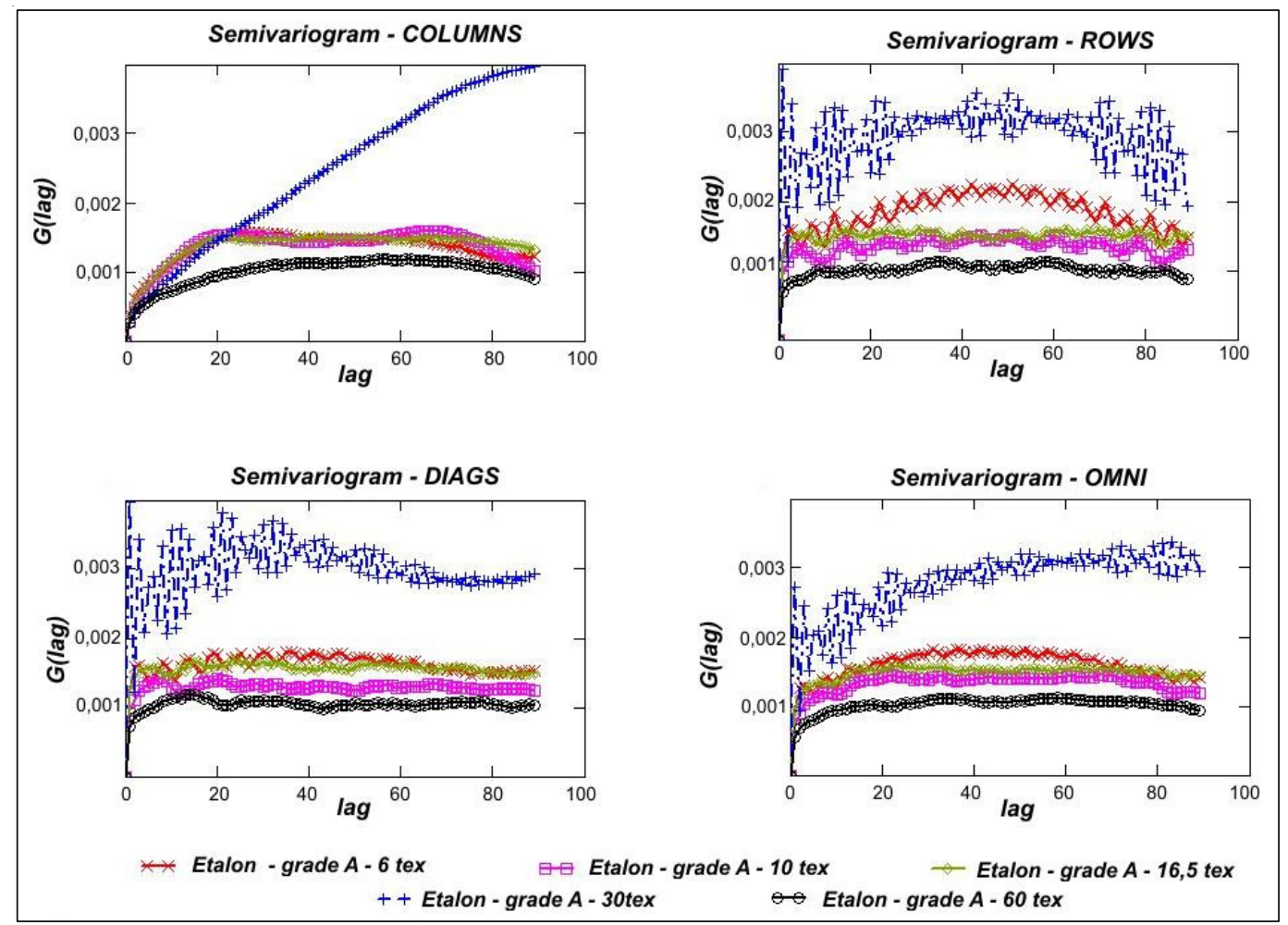

Figure 9. Directional semivariograms - etalons grade A - step 15 pxl.

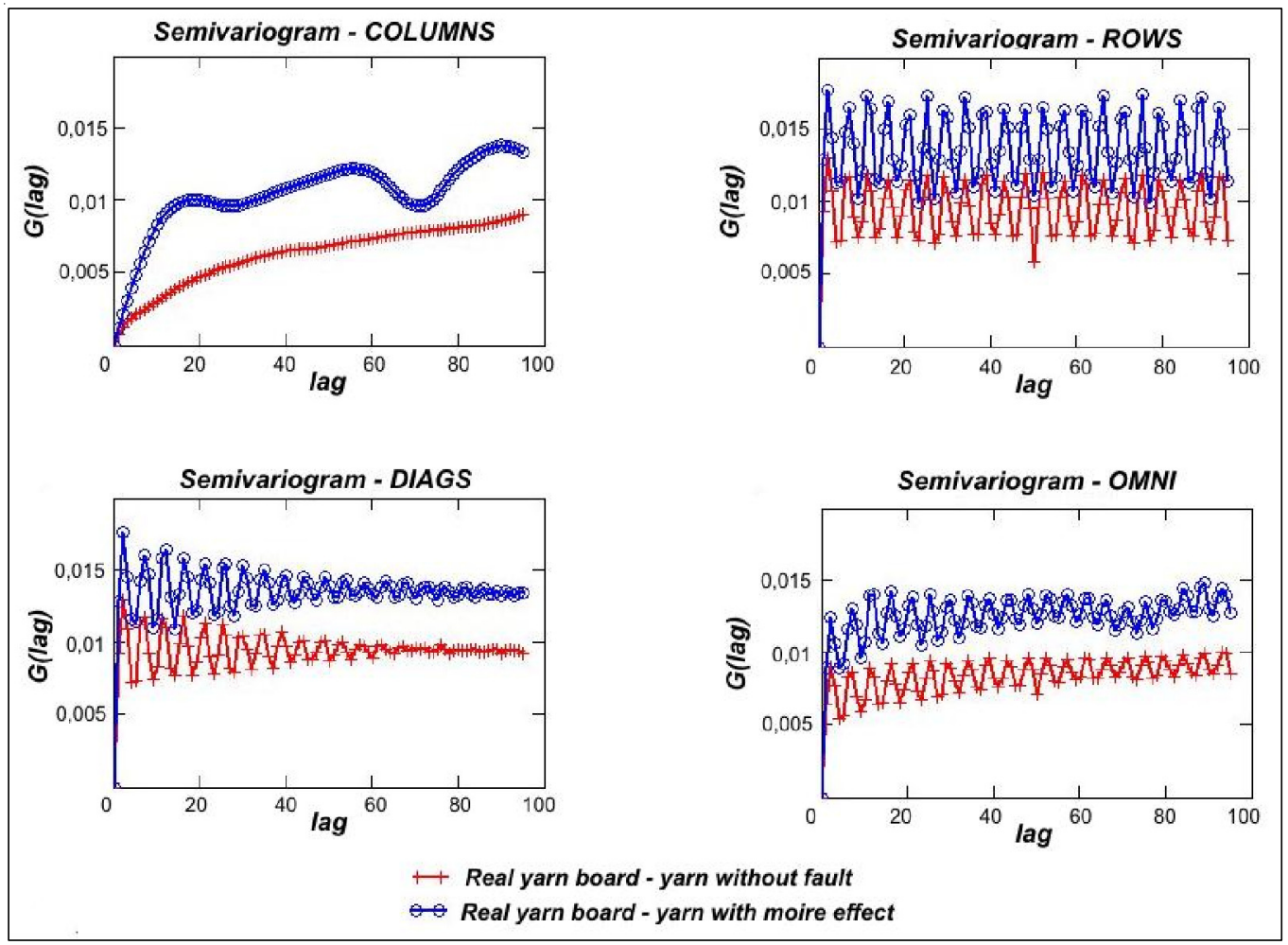

Figure 10. Directional semivariograms - real yarn boards - step 15 pxl.

of grade A are shown. The course of a curve is influenced by yarn fineness and winding density in combination with the parameter step. Therefore to evaluate the yarn appearance in an area, it is necessary to compare yarn boards with the same yarn fineness and the same winding density.

The etalon grade A with yarn fineness 30 tex showed signs of damage in certain areas; the yarn was more hairy, the winding showed signs of periodical fault, and the yarn was more irregular compared with other etalons of grade A. Therefore, the semivariograms of the etalon A with yarn of fineness 30 tex has the highest values. This damage, together with the combination of yarn fineness, winding density, and size of parameter step can influence the course of the curve.

\section{$\underline{\text { Real yarn boards }}$}

Real yarn boards were used for this experiment too. The rotor spun yarns (fineness 50 tex, 100\% CO) of two qualities; yarn without faults (Figure 2a), and yarn with moiré effect (Figure $2 \mathrm{~b})$ were wound on a black board with the same winding by 
the Planiscop device. The directional semivariograms of greyness degrees are shown in Figure 10.

The semivariograms with step at $3 \mathrm{pxl}$ have nearly identical courses in the case of both yarns [18]. Thus, they cannot be used for evaluation of surface unevenness, but they could be useful for the evaluation of the regularity of winding.

From the course of the semivariogram with step at $15 \mathrm{pxl}$ (Figure 10), it is evident that the worsening appearance of the yarn board shows itself as a higher position on the semivariogram curve. This is due to the yarn irregularity causing a greater fluctuation in the average greyness degrees between the observed square fields. The period of variation of the curve is identical and confirms the fact that the yarn was wound on the board by means of one Planiscope device with the same winding fault. In the case of the semivariogram in the direction of columns and in direction of rows, yarn irregularity expresses itself as a variably growing curve compared with the linearly increasing course for a yarn board without yarn faults.

\section{Conclusion}

A study of using directional semivariograms for the evaluation of appearance of yarn wound on the board was presented. We used etalons of yarns from CSN 800704 - cotton yarn, grade A (the best yarn appearance) to grade $F$ (the worst yarn appearance), and real yarn boards with yarn of various quality. For determination of the ideal course of a semvariogram, graphical simulations of ideal yarns wound on the board of a size corresponding to the etalons were created. Standard yarn boards and real yarn boards were scanned and then, using Matlab, directional semivariograms of greyness degrees were constructed. These functions expressed fluctuations of greyness degrees of the image depending on various distances between square fields of a pre-set size. The courses of the curves were then analysed for dependence on both the yarn board appearance and the program setting. The course of the semivariograms depends on the parameter step and this parameter specifies the size of the square by which the image is divided before the construction of the curve. With an increasing value of this parameter the curve is increasingly smooth. At low values of the parameter step, the combination of semivariograms in the direction of rows and in direction of columns can record the structure of yarn winding on the board, i.e., regularity of winding. At higher values of parameter step, it is possible to study the unevenness in the appearance of the yarn surface. With a deteriorating appearance the values of the semivariograms are higher and fluctuate more. This is due to the fact, that the yarn board appearance is non-balanced at higher yarn unevenness, and average greyness degrees vary more between the observed square fields. The course of the semivariograms is also influenced by the total size of the observed area.

\section{Acknowledgement}

This work was supported by Research Projects Textile II No. $1 \mathrm{M} 0553$ and was published in 18th conference Strutex Structure and Structural Mechanics of Textiles hold in November 2011 in Technical University of Liberec in Liberec.

\section{References:}

1. ASTM Standard Test Method for Grading Spun Yarns for Appearance, 2255-90, (1990).
2. CSN 800704 Determination of yarn appearance, (1993).

3. KIM, Y. K.; LANGLEY, K. D.; AVSAR, F.: Quantitative grading of Spun Yarns for appearance, Journal of Textile Engineering, vol. 52 (2006), No. 1, pp. 13-18, ISSN 13468235.

4. SEMNANI, D.; IATIFI, M.; TEHRAN, M. A.; POURDEYHIMI, B.; MERATI, A. A.: Development of appearance grading method of cotton for various types of yarns, RJTA, vol. 9(2005), No. 4.

5. BERAN, L.; ŠRÁMEK, R., VYŠANSKÁ, M., HORÈIÈKA, J., ET ALL: Optical evaluation of a yarn being continuously wound on the surface, Proceedings of 16th International Conference Structure and Structural Mechanics of Textiles, ISBN 978-80-7372-542-6, Liberec, December 2009, Technical University of Liberec, Liberec, (2009).

6. MILITKÝ, J.: Probability model of nonwovens unevenness, Proceedings of 7th international conference Structure and Structural Mechanics of Textile, pp. 193-198, ISBN 80-7083442-0, Liberec, Technical University of Liberec, Liberec, (2000).

7. MILITKÝ, J.; KLIĖKA, V.: Characterization of textiles mass variation in plane, Proceedings of 5th world Textile Conference Autex 2005, pp. 750-755, ISBN 86-435-07091, University of Maribor, Faculty of Mechanical Engineering, Department of Textiles, Maribor, (2005).

8. [8] JIRÁSKOVÁ, P.; MOUĖKOVÁ, E.: Unevenness of flat textiles and its quantification, Proceedings of 3 rd International Textile, Clothing \& Design Conference-Magic World of Textiles, pp. 612-617, ISBN 953-7105-12-1, Faculty of Textile Technology, University of Zagreb, Zagreb, 2006.

9. MOUĖKOVÁ, E., JIRÁSKOVÁ, P., URSÍNY, P.: Surface unevenness of fabric, in Woven Fabric Engineering, Sciyo, ISBN 978-953-307-194-7, Rijeka, Croatia, (2010), pp. 195 $-216$.

10. MILITKÝ, J., KLIĖKA, V.: Some tools for Nonwovens uniformity description, Proceedings of 4th International Textile, Clothing \& Design Conference - Magic World of Textiles, pp. 842-848, ISBN 978-953-7105-26-6, Faculty of Textile Technology, University of Zagreb, Zagreb, (2008).

11. MILITKÝ, J.; RUBNEROVÁ, J.; KLIĖKA, V.: Spatial statistics and unevenness of surface mass of non-woven textiles, Proceeding of 7th national conference Strutex, pp. 199203, ISBN 80-7083-668-7, Liberec, December 2002, Technical University of Liberec, Liberec, (2002).

12. SUH, M., W.: An electronic Imagining of Fabric Qualities by on-line yarn data, Available from www.ntcresearch.org/ pdf-rtps/AnRp01/I01-A1.pdf Accessed: 2005-02-01.

13. SUH, M., W.: An electronic Imagining of Fabric Qualities by on-line yarn data, Available from www.ntcresearch.org/ pdf-rtps/AnRp01/S01-NS12-A2.pdf Accessed: 2005-02-01.

14. BREZINA, M.; MILITKÝ, J.: Complex characterization of textile surface, Robust'2002 - proceeding of twelfth winter school JÈMF, pp. 50-58, Hejnice, January 2002, Union of Czech Mathematicians and Physicists, Prague, (2002).

15. JIRÁSKOVÁ, P., MOUĖKOVÁ, E.: New evaluation methods of woven fabric unevenness, Autex Research Journal, vol. (10), No. 2, pp. 49-54, ISSN 1470-9589.

16. CRESSIE, N.A.C.: Statistics for spatial data, J. Wiley, ISBN 0-473-00255-0, New York, (2002).

17. NECKÁR, B.: Príze - Tvorba, struktura, vlastnosti, SNTL, ISBN 80-03-00213-3, Praha, (1990).

18. MOTÝLOVÁ, L.: Objective evaluation of yarn appearance in area, Diploma work, Technical university of Liberec, Liberec, (2011). 